\title{
Analysis of the Use of Virtual Reality Technology in Gamified Learning
}

\author{
Yengin D. ${ }^{1}$ \\ Bayrak T.2
}

${ }^{1}$ Deniz YENGiN, İstanbul Aydın University, (Turkey)

e-mail: denizyengin@aydin.edu.tr

${ }^{2}$ Tamer BAYRAK, İstanbul Aydın University, (Turkey)

e-mail: tbayrak@aydin.edu.tr

\begin{abstract}
Virtual reality (VR) which is the world's state-of-the-art learning technology, is an innovative way of teaching students anything and increasing their attention. Students enter to an educational adventurous world through special headphones and devices. VR labs that contain this technology, expand the borders of schools, affordably. Cost of research centers such as science laboratories which are today, considered as luxury, decreases by means of VR labs and VR technologies inside those labs. Since VR technology is based on computers which are already present at schools, it is possible to increase students' success on a large scale for every school. The most important gains of VR labs are savings of time and space. Students who use VR as an educational tool, explore unreluctantly, adjust to studies easily and subjects of education quickly. VR systems which provides a real time virtual learning environment, offers simulation scenarios to improve students' problem solving and analytical skills. By means of these systems students will be able to solve problems through researcher and cooperative experimental activities. Scenarios are being developed in accordance with current math and science classes by using games and digital modelling. Students can use these systems to quickly interact with anyone and share their ideas and experiences. VR systems can also help students develop their language skill by encouraging them to participate in discussions, speeches open to general public, live audio communications and broadcastings. For students to receive feedback and have more time will have a positive contribution to their studies. Starting from this point of view VR technology is at the center of the study. By using gamified learning analyze through VR technology, some important data will be presented about the development of VR technology as a new media application of the future.
\end{abstract}

Keywords: Virtual Reality Technology, Gamified Learning, Virtual Education

\section{Introduction}

$20^{\text {th }}$ century is a period of time that functioned as a bridge for communication and information technologies. During this time, media technologies underwent a transformation and left its place to new media technologies. Science, which is at the basis of this fast conversion, is the most striking characteristic of these rapid technological developments, globalization and information society. Information which is the most essential building block for technology to develop, is at the center of the production. In parallel with the developments in communication technology, it is now entered to a new period where access to information has become easier. Rapid economic, social, scientific and technological developments emerging today, change our lifestyles to a large extent.

Technological developments set the framework for the new concept of communication. A lot of important changes occurred in $20^{\text {th }}$ century's information society in this sense. Changes are easily noticed when means of communications are examined. Especially with the invention of electricity, communication gained a completely new meaning. McLuhan's statement, "the medium is the message" signifies the importance of communication (2001). At this point, the importance of how information is conveyed in new communication mediums comes to the forefront.

Innis puts an emphasis on how new technology which plays an important role in the transformation of communication, "snatches" with the monopolies of conventional information and how 
it creates another information monopoly which is ruled by another group. In this sense he tries to show that communication technologies affect and shape society forms (Postman, 2004: 18). Variety of communication channels in transformed communication technologies generated information and knowledge mines. In this abundance, mankind suffocates because they don't exactly know how to use it and faces with information overload. Especially VR environment offering means, are able to present a different world to users. Baudrillard, defines simulation which is at the basis of VR as "reproduction of the real through codes and models, just like computerized simulacra are the functions of their own programme" (2005:83). In today's world where the differences between virtual and real are decreasing day by day and daily life give its place to virtual life, VR systems that are both a new communication channel and carry the characteristic features of new communication mediums, carry the user from a passive role to an active one. Users' control on virtual environment messages increases and by means of interfaces, users become a part of experiences.

Rapid developments in technology are dragging us into new environments. These environments make progress depending on time and developments in technology. Developed systems undergo a process and appear in a different form. In order to explain this change of form we need to know what transformation is. Change is an act or process through which something becomes different. It also has several meanings such as; act, translocation or transition from one situation to another, development, growth and development, alienation from conventional thoughts and stereotypes, develop a method which will provide higher efficiency and effectiveness. All of these meanings indicate a transition from a negative case to a better one. In addition to that change is also the action or process of replacing someone or something with a new one.

When we look at today, the word transformation may not be understood comprehensively. It's when historical development of a phenomenon is looked at, the meaning of the word transformation is perceived properly. In this historical process that we mentioned above, communication has transformed from individual into mass. If the aim is basically taken as conveying a message from source to recipient; it becomes clear that the essence didn't change. However, it is a big fact that form has changed through thousands of years long process. In the communicative plane where the process works this naturally, completion of a transformation triggers another.

Combination of communication and technology made the transformation inevitable. One of the most important products of this transformation is VR technology. Virtuality which is the base of the technology, is a means, machine, system, examination of functioning of a specific phenomenon, a mockup made in order to show or explain, an artificial reproduction via a computer program. Baudrillard defines simulation as "The simulacrum has no chance of hiding the truth- since it is truth that hides the fact that there is none." (2005). Procedural reality which is the image of the reality comes to forefront.

\section{Concept of Game}

Game is defined as a recreational activity that has specific rules, gambling, a skill cause astonishment, a form of interpretation of an actor's role in cinema or theatre, overall acts performed accompanied by music, a form of literature written in order to be performed on stage or dubbed, show, spectacle, any kind of competition done to improve both psychical and mental skills, a kind of competition base on agility, any kind of unexpected move done to beat opponent in wrestling, result of a tennis match or backgammon played and ended by scoring certain points, cheat, deception, wile and scheme (Turkish Language Dictionary 2019) The concept of game is a way of thinking and movement, that is suitable for different movement and thinking systems in every aspect and it is designed according to the behavior of others and the conditions of the situation, contrary to the conventional behavior patterns.

Game is based on psychical, cognitive, linguistic, emotional and social development and directed or not directed to a goal, played with or without rules but individuals always with willingness and enjoyment of individuals and a part of the real world and the most affective learning process for individuals. Huizinga who has studies about game, defines it as an activity that proceeds within its own proper boundaries of time and space according to fixed rules. According to Huizinga, game is older than culture and is not a serious activity. Primarily, every game is a voluntary activity at the basis. Game creates an order and it is also the order itself. Every game has its own rules. There is no value of daily life's rules and customs inside the playground. We are different and act in a different way. Temporary cancelation of this "Ordinary World" is seen even in the childhood. This, also seen in adults who participated in liturgical games towards worshipping in primitive societies. Game is a battle for something 
or qualify something in a representative manner (Huizinga, 1995). In sum, game is a free activity. It is consciously kept out of daily life and not adopted as a serious job. Player devotes oneself to game intensely and utterly. In this activity player doesn't expect a financial gain, profit or benefit. Its formation is in its own time and space boundaries with fixed rules and order. There are several studies done on game in the litterateur.

Berne defines game as "an ongoing series of complementary ulterior transactions progressing to a well-defined, predictable outcome." in his book "Games People Play". Berne classifies game into six categories. These are; number of players, currency used, clinical types, zonal, psychodynamic and instinctual (2019:44). Different characteristic features of games make it harder to collect them under a single title. Various resemblances such as height, face structure, eye color, gait and temperament are found in games as well (Wittgenstein; 2007:52). Because of that, instead of looking at common features of games it is more useful to examine them in terms of resemblance or affinity.

Huizinga defines game as "a thing which does not exist actually, but which fatally absorbs the players from top to toe while the freedom of working is going on outside consciously and while the "accustomed life", that is the existing life, is going on as it is". It is an activity connected with no material interest, and no profit can be gained by it. It proceeds within its own proper boundaries of time and space according to fixed rules and in an orderly manner (1995: 13). Caillois defines game as "activities with the characteristics of being free, separate, uncertain, unproductive, rule-bound, and make-believe" (2011: 10-11). Avedon and Sutton define game as "at its most elementary level then an exercise of voluntary control systems in which there is an opposition between forces, confined by a procedure and rules in order to produce a disequilibrium outcome." (1971: 7). Salen and Zimmerman define game as "a system in which players engage in an artificial conflict, defined by rules, that results in a quantifiable outcome" (2004: 96). While Juul's definition of game is "a rule-based formal system with a variable and quantifiable outcome, where different outcomes are assigned different values, the player exerts effort in order to influence the outcome, the player feels attached to the outcome, and the consequences of the activity are optional and negotiable." (2005: 36). Game is an entertaining, optional, indefinite activity which is usually out of real world and has its own distinctive rules and culture. In general, game compels attention with features such as boundedness, having rules and not being serious.

Huizinga who puts emphasis on boundaries of game, states that game has a "Magic Circle". Magic circle represents a world with boundaries that can be both entered and exited, includes rules related to game and a certain result. According to this theory every game has a magic circle. Players must enter to this invisible Magic Circle to play. In this circle, games are played in line with fixed or known rules. One of the most prominent examples can be given to this magic circle concept are wresting and Japanese sumo.

In the direction of these approaches game is a not serious phenomenon which has rules, boundaries limited with entrance and exit and not real although it makes people feel like it is by drawing people into an activity. Features such as boundedness, having rules and not being serious are transferred into new mediums labeled as new. In this context, new media concept gains importance.

\section{Gamified Learning in Virtual Reality as New Media}

The term "media" has a quite disputable definition. When defined as communication between people; communication methods that people who lived million years ago used must be examined as well. In this sense, new media, might not be an ideal term to use for classification of technologies. However, this term came to forefront as a term linked with technological transformations happened in near time in the context of communication and gained recognition internationally. New communication concept is in a fast evolution process. McLuhan's "Global Village" concept, still continues through effects of technological changes.

Manovich analyzes new media mediums under five principles. These are; numerical representation, modularity, automation, variability and transcoding (2001: 27-48). These principles shed the light on transformation of new media mediums.

Numerical representation is formed of media codes. Objects of new communication medium are communication sources created in computer or transferred to computer from an analog system. Data are countable and consist of digital codes. 
Modularity is a feature that allows making changes on any component while it gathers different components under a single roof. Different components are able to come together in order to create one item in a different form. Macromedia Director software which allows multimedia writing can be given as an example to that. We can upload different and independent items in this software. Uploaded items are used, interpreted and reproduced into single item by users.

Automation is the system which is produced by media without a user. Numerical representation and modularity need a system to build a structure. This system mostly enables operations that user contribution is small, to be done automatically

Variability is a principle that enables an item to appear in more than one form. Item, which is the production of numerical representation and modularity, doesn't have a fixed form and can transform into different forms.

Transcoding includes structures' that consisted from codes to transform between each other. Transformation between formats are emphasized in the new communication medium language. In the conventional communication medium, a flexible structure is out of question. In the new communication medium, a flexible structure and transformation between different formats corresponding with this structure are enabled. This occurs through intersection of numerical representation, modularity, automation, variability and transcoding principles.

Lister examined characteristic features of new communication mediums under the "technological obligation" roof. These are; digitality, interactivity, hyper textuality, dispersal and virtuality (Lister, vd., 2003: 9-44). Just like Manovich's principles, these principles also make clear transformation of new communication mediums. According to that;

Digitality; is the expression of data according to binary system. It's a digital or digital numberbased phenomenon. While physical items are used in analog environment, items in digital environment are signified with codes consist of only numbers zero and one. It enables data to transform from analog to digital and creates new data by using digital environment. It's easier to process digital data than the analog data. Access to data in digital system occurs fast.

Interactivity is the case of user's ability to interfere with content of data. Users can direct the new communication medium in the direction of their aim. User's ability to direct data content in the direction of their personal aim through interaction is an important characteristics of new communication medium. Interaction phenomenon turns user into active role from a passive one in the communication process. User is able attach anything to the content. Interaction feature and personalization of the content increases both the attendance and options of the user.

Hyper textuality is the case of which texts are interrelated. Hyper means, above or beyond. The prefix hyper, is used for its "beyond" meaning in order to indicate difference and innovation between digital and analog. Hypertext is the networking of texts within itself. In this context, text is able to reach texts above itself through created network. Hypertext mediums attract attention with limitless data acquisition, sharing and updating features. According to Lister who benefited from Vannevar Bush's study "As We May Think", in the formation of hypertext concept, Bush's explanation on operation logic of human mind through relations had an influence on it. While Lister explains hypertext as a feature of new communication medium; Manovich explains it under the hypermedia roof. Hypermedia is a medium type made of different components such as image, audio, video and text. At this point hypertext is a subcategory that hypermedia created, and it only consists text.

Dispersal is the case of which information is conveyed by being customized and without using the host system. In the understanding of conventional media, there is production and distribution process subject to a central structure. In the new communication medium, there is no homogenous receiver group who will receive messages. Relationship between sender and picky receiver, is increasing. In order to keep up with the developments in network technologies, media companies are driven to a new understanding from the conventional one. According to Lister, differences between consumer and producer are decreasing due to dispersal feature. This feature of new communication media is able to switch consumers' position into producers. 
Virtuality, is the presentation of the copy of reality. Virtuality which means not real, is the most important characteristic of the new communication medium. Virtuality brings the concept of virtual reality along with itself. In these mediums the copy of the reality is served to users in the prepared reality environment. The important thing in here is that how much of a person is isolated from the real world. Users are able to assume different personalities. At this point, new communication medium creates a virtual world by effectively simulating an event that might occur daily.

Common point of these principles is digitalization. A digital universe is being mentioned here. The items exist in new communication mediums are expressed in numbers. Items that are switched to digital from analog or the ones produced in digital in a different form, can be variable by transcoding through automation with modular structure feature.

When new communication medium features are examined, digitality appears as a main feature. Digital universe is completely expressed with numbers and digitality feature is added to communication medium. Interaction has an important place in the new communication medium. During the communication process, for receiver to become sender or source's ability to control over the message is interaction (Geray, 2003: 18). In the recent period in which interaction is at forefront we come across to expressions such as information society, knowledge society, technology society or network society. While Yoneji Masuda emphasizes information society; Manuel Castells emphasizes the network society (2005). There are common intersections in today's communication medium where conflicts between concepts created. Digital mediums and users are at the common point of this intersection.

Users define their identification completely through digital medium channels into this medium and save them. In binary system mediums, users get digitalized and transform into 0 and 1's. This transformation is also stated as "Byte Society". Accelerated data exchange via information technologies, actualizes Marshall McLuhan's concept of "Global Village". Extensiveness of information technologies and internet's participation into this facilitates free circulation of information.

For the media, which has a wide range and includes all these definitions, what is new isn't the opposite of old. The new is built on the basis of the old. The new also consists the old. The old transforms into the new. Mediums which were defined as new, are recognized through the examination of different features, independent from time. For new to take the concept of old, depends on the technology it has. New communication mediums, an extension of digitality, represents mediums that prevents data loss.

Table 1. Principles of New Media

\begin{tabular}{|l|l|l|l|}
\hline Roger Fidler & Lev Manovich & Martin Lister & Dennis McQuail \\
\hline $\begin{array}{l}\text { Coexistence and } \\
\text { Coevolution }\end{array}$ & $\begin{array}{l}\text { Numerical } \\
\text { representation }\end{array}$ & Digitality & Interactivity \\
\hline Metamorphosis & Modularity & Interactivity & Socialization \\
\hline Propagation & Automation & Hypertextuality & Media Richness \\
\hline Survival & Variability & Dispersal & Automation \\
\hline Merit and Need & Transcoding & Virtuality & Happiness \\
\hline Delayed Adoption & & & Privacy \\
\hline & & & Individualization \\
\hline
\end{tabular}

(Source: Yengin, 2012: 53)

In this context, the communication environment is at the position of one of the basic fields where the human thought is shaped. This field is updated by mass communication means which are shaped by the technological developments. This state of being updated makes it obligatory to add the word 'new' to it. The communication environment adds reflections of today's developments into its discoveries without losing its essence, transforming through structuring and actualizing a new communication process. In short, the new communication medium is a communication area with a structure built upon the digital coding system, where interaction occurs at high speeds in parts distinct from one another.

New media, defined as information technologies that typically uses microprocessor and computer competences, gives "interaction" opportunity between users, and information and user or make this, obligatory (Timisi, 2003: 81). In the light of these definitions new communication medium is defined as a new, different area where individuals practice the communication process and it ensures 
transformation of the technique that individual obtained. New communication medium transforms education which plays an important role for individuals to become a socialized being just like in every field. Education which changed its form with the developments on technology, ensures individuals adaptation of information society easily. Especially, VR technology which appeares as a result of rapid development of computer technology and integrates individuals to new communication medium, caused re-configuration of known education methods. Just as this technology directly affected production and consumption it has also affected education and as a result of that new education models which is defined as virtual education where realistic visuality is at front, appeared.

Before stating the origins of the virtual education which appeared as a result of global technological changes, it will be useful to define the concept of "virtual" briefly. In English the word "virtual" is used to define events that do not exist physically but only exist depending on the effect that is produced. Virtual concept is very broad in terms of meaning and is used worldwide and in many cases, it is frequently mentioned without distinction between concepts such as open and distance learning. In this sense, virtual concept is used to refer convergent systems such as interactive remote conference technologies and transmission via such fields as distributed learning, e-learning, network-based learning, web-based learning and computerized learning. In a virtual education provided in any field, how the information and technologies are applied must the focus in order to determine the purpose of usage of virtual concept. Some people claim that the era defined as revolutionary in communication technologies was 1960's, while other people claim that it was 1980's. The difference of VR technology, which has emerged in this period, where new communication technologies were developed, is that conventional technologies are limited to usage width, served contents and abilities technology supplied. When we classify this boundedness while radio and television considered as conventional media, technologies such as video, video text, teletext, cable and satellite broadcasting are placed in the new media category. However, today's technology also includes a constantly expanding communication technology network such as microprocessors, cabled tv, fiber optic, satellite broadcasting, word processor, e-mail, internet and video conference.

"Virtual Reality" concept is a three-dimensional simulation model created by computers that makes participants feel as if it's real and enables mutual communication with a dynamic environment. Up till today from show business to complex science experiments conducted in the field of medicine, VR has found several implementation areas. In this sense media which is simulated by computers is called virtual reality. Most of the VR environments consist of visual experiences obtained from a computer screen. Virtuality which comes from the term in Latin "virtualis", is used related with objects or places that do not physically exist but thought to be exist by illusions. Actually, the term comes from the verb "imagine". In this respect, what is virtual isn't an object that is real or exist. On the other hand, virtual doesn't mean the opposite of what is real or wrong. Thus, it can be thought that concept of VR is any form of life that is not real.

Table 2. Features of Conventional and Virtual Education

\begin{tabular}{|l|l|l|}
\hline \multicolumn{1}{|c|}{ Factors } & \multicolumn{1}{|c|}{ Conventional Education } & \multicolumn{1}{c|}{ Virtual Education } \\
\hline Time & Dependent, time application & Independent, continuous \\
\hline Place & Dependent, limited & Independent, limitless \\
\hline Transfer & Based on technology & Not based on technology \\
\hline Speed & Slow & Fast \\
\hline Educational Broadcast & $\begin{array}{l}\text { Controlled, systematic, face to } \\
\text { face, limited time }\end{array}$ & $\begin{array}{l}\text { Uncontrolled, unsystematic, } \\
\text { distance learning, unlimited } \\
\text { time }\end{array}$ \\
\hline Skill - Quality & $\begin{array}{l}\text { Depends on teachers' skills, } \\
\text { depends on students' } \\
\text { processes. }\end{array}$ & $\begin{array}{l}\text { Independent from education, } \\
\text { commonly employability }\end{array}$ \\
\hline Flexibility & Non-flexible and re-configured & Flexible and re-configured \\
\hline Competence & Depends on the situation & Depends on the situation \\
\hline Benefit & Limited & Unlimited, common \\
\hline Investment & High cost & Low cost \\
\hline Operation & High cost & Low cost \\
\hline
\end{tabular}

(Source: Cebeci, 2004)

Education isn't associated with only classrooms anymore. At home and game learning methods, has become as important as conventional education methods. In this context, along with the 
globalization of information and access to it; having the understanding of how such access is enabled has gained more importance than the information itself. What is important in a world where everyone has immediate access to information, is to know the access to any information, synthesize from these information and also implementing them. Along with being a means used in this transformation, it is also seen as an element which can digitize data and turn it into electronic environment. While the internet world fastens privatization of life, it also explores the difference between real and virtual (Davies, 1998; Schank, 2000). The gap between the ones who have information and communication technologies and the ones who don't use it, is expanding. Economical outcomes accompanied by cases stated above causes information rich or information poor individuals, groups and dipole societies. This power which is defined as digital discrimination forces education to change.

Virtual education is a product of new world order fundamentally produced through communication technologies; a system developed which education alternatives offered to "interactive" student "without any limitation of time or space" (Karasar, 2004). As can be understood from this definition virtual education is any kind of education applied in electronic environment and several classification methods are adopted in this field based on the technology used. In Turkey, virtual education practices were started under the name of METU Certificate of Information Institute in 1997 and these practices has been developed up to today (Onay and Yalabık, 1998). Along with this, one of the most crucial attempt made was the establishment of Directive of Distance Education Based on Interuniversity Information and Communication Technologies by The Council of Higher Education on $14^{\text {th }}$ December 1999. Activities of distance education began to be conducted in Turkey after the studies of National Information Committee. In addition to that, with the accreditation of some of the web-based classes in virtual medium, it was also ensured that universities requested same contents received them.

For education, which is an important necessity for modern societies, some affective methods were formed. One of these methods which makes education of people easier, is gamification. Today, people play games to have a good time, move away from their mental problems or solve problems by gamifying them. Contrary to an ancient concept of game; gamifying is a new phenomenon. In gamification where a way of thinking and rules pertained to game applied in order to attract users' attention and solve their problems (Zicherman and Cunningham, 2011) meaning of the concept and how it can be used in education gained importance. For a very important field such as education to have rules and components pertained to game, leaves a positive effect on individuals.

\section{Findings}

In the context of utilization and effects approach, a research has been conducted with a group formed of 50 students of İstanbul Aydin University Faculty of Communication between the dates April 1, 2019 - May 1, 2019 who were randomly chosen to deduce the negative effects related to experiences on utilization of VR devices and to bring out the relationship between demographic characteristics and/or factors. For findings obtained from the research VR tools have been used to students, and reactions they gave before and after watching and experiencing utilization of gamified learning device were analyzed and evaluated in the scope of gamified learning in virtual reality which is a new concept in terms of communication. Primarily, a questionnaire consists 36 questions concerning their demographical information were asked from participants to fill it out. After the questionnaire was filled out VR headsets have been worn to participants. During user experience, it was observed to determine whether experience has any effects, questions concerning negative effect felt during the experience were asked between every game and it was requested from participants to rate it from 1 to 5 .

Also, video of participants' utilization experience is recorded. Participants were informed before the experience about what kind of a research they will be participating and what they need to do, and a letter of consent was signed by participants. After the VR headset experience participants were asked to fill out a questionnaire consists 52 questions concerning gamified learning in VR.

First of all, participants' time and frequency of technology usage was determined in the questionnaire. This determination is important for the understanding of prone to computer-based technologies such as VR. The main reason for this is that individuals used VR technology, can use such technologies for a long-term to the extent of their proneness. For instance, participants who wore VR goggles, started to feel dizzy and nauseous after 20 minutes. However, the time of usage of these technologies is extended on people who are prone to these technologies by other means (Algül and at all, 2018). This situation ensures high level of concentration on individuals who use VR technology. 
According to data received from the research; the most frequently used technological device is mobile device. Mobile devices which have a pretty rich digital content, offers convenience to users in terms of portability. Because of that, users are able to use these devices anytime, anywhere. In the ranking laptops, tablet computers, desktop computers and VR goggles follow mobile devices in that order. Primary reason behind the less usage of VR goggles compared to others is that this technology is expensive and causes cable problems. In this respect, technology's expensiveness and symptoms seen in participants after 20 minutes of experience poses an obstacle in front of spreading of user-based VR technology.

\section{DURATION AND FREQUENCY OF TECHNOLOGY USAGE}

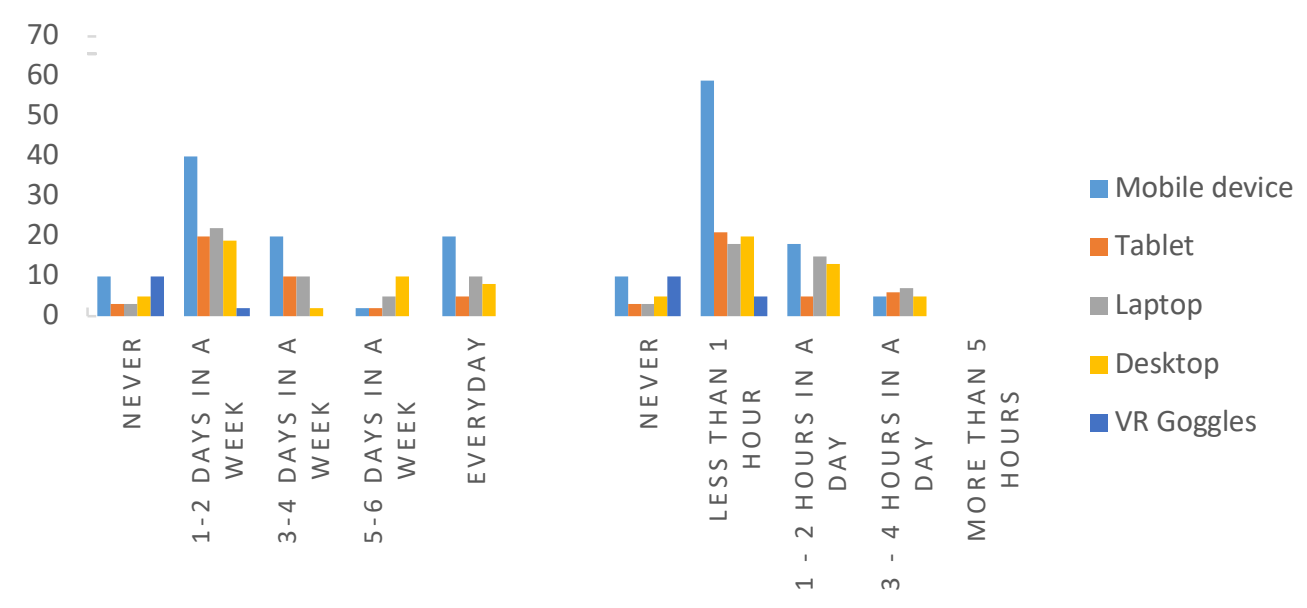

\section{Diagram 1. Comparison of Technology Usage Frequency.}

During the observation, a monitoring key was used in scope of litterateur in order to prevent missing any observation data, this way user's reaction given during the experience of VR goggles performance is observed easily. Reactions given during the research but didn't appear on monitoring key also recorded on monitoring key. In this scope, participants' subjective reporting became important. As a result of observations made, data were gathered, and it was determined that how effective gamified learning is. Recorded observation data is included to scope of analysis by turning into numerical expression.

Research part of the study divided into 3 days of time period. Tilt Brush which is a part of world's greatest digital game platform Steam, is chosen to determine differences between VR gamification learning and classical learning and difference of learning in virtual reality. The most important reason behind this choice is that, this program gives the opportunity to learn virtual drawing in gamified form. In this context, study is performed with one of the most important means of virtual reality technology, HTC Vive.

The study which its first period was designed on classical learning, was divided into three periods and lasted three day. On the first day, 60 minutes of classical learning practice was applied in the morning, afternoon and evening with 20 minutes long sessions. In this practice, lessons are given in classical way and students were asked to make same drawing of a virtual drawing done in Tilt Brush, classically with hand. A test was done after every 20 minutes long practices and participants' motivations were determined. According to that, after the morning practice of 20 minutes long classical training, no motivation loss was observed. In the second session which was held in the afternoon, after the 20 minutes long classical training and practice a partial loss of motivation was observed. In the evening session after 20 minutes long classical training and practice motivation loss was observed in the whole group. 
On the second day, 60 minutes of digital environment learning practice was applied in the morning, afternoon and evening with 20 minutes long sessions. In this practice, lessons were given digitally in a computer environment, participants were requested to draw a virtual drawing which was drawn in Tilt Brush, in a programme similar to Tilt Brush. A test was done after every 20 minutes long practice and participants' motivations were determined. According to that, after the morning practice of 20 minutes long classical training, no motivation loss was observed. In the second session which was held in the afternoon, after the 20 minutes long classical training and practice no motivation loss was observed. In the evening session after 20 minutes long classical training and practice a partial motivation loss was observed.

On the third day, 60 minutes of gamified learning in virtual reality practice was applied in the morning, afternoon and evening with 20 minutes long sessions. In this practice, lessons were given through virtual reality technology HTC Vive and participants were asked to draw a virtual drawing using Tilt Brush. A test was performed after every 20 minutes long practice and participants' motivations were determined. According to that, after the morning practice of 20 minutes long classical training, no motivation loss was observed. In the second session which was held in the afternoon, after the 20 minutes long classical training and practice no motivation loss was observed. In the evening session after 20 minutes long classical training and practice no motivation loss was observed.

Table 3. Features of Classical Learning, Learning in Digital Environment and Gamified Learning in Virtual Reality

\begin{tabular}{|c|l|l|l|}
\hline Duration & Classical Learning & $\begin{array}{l}\text { Learning in Digital } \\
\text { Environment }\end{array}$ & $\begin{array}{l}\text { Gamified Learning in } \\
\text { Virtual Reality }\end{array}$ \\
\hline 20 minutes & High Motivation & High Motivation & High Motivation \\
\hline 40 minutes & $\begin{array}{l}\text { Partially High } \\
\text { Motivation }\end{array}$ & High Motivation & High Motivation \\
\hline 60 minutes & Motivation Loss & $\begin{array}{l}\text { Partially High } \\
\text { Motivation }\end{array}$ & High Motivation \\
\hline
\end{tabular}

According to data obtained from pretests, practices and posttests; there are differences between classical learning, digital learning and gamified learning in virtual reality in the context of motivation. In students who participated in 60 minutes long pretest, practice and posttest research processes for 3 days, a noticeable loss of motivation is observed in classical learning after 20 minutes. Students who were partially motivated lost all of their motivation after 40 minutes. It is observed that students are more motivated in digital learning compared to classical learning however they lost their motivation partially after 40 minutes. Based on the data gathered from pretest, it is understood that non-stationarity image transfers that digital environment offers has a profound effect on that. Lastly, it is observed that in pretest, practice and posttest, gamified learning in virtual reality doesn't cause any motivation loss. In this context, it is seen that virtual reality has a huge advantage compared to classical and digital environment learning., removed it is a fact that people will be benefiting more from virtual reality which transcludes user to a new environment as if it is real, especially, when symptoms seen in new users of VR goggles after 20 minutes of using it.

\section{Conclusions}

Virtual reality is a reality established through benefits from technology's facilities with the help of tools compiled from the nature. Even though used tools and adopted methods don't fit to the reality in nature; it arouses a feeling of reality in terms of outcome and so brings out the created reality with the help of incorrect images. Illusion of reality is effectively developed in the designed image, by means of computer technology. Digital technology allows objects to be turned into pixels by effect specialists. In this sense, it is a fact that we will be living in a world full of visual and audial messages in the future.

Mimesis, which means impersonation in Greek, is emphasized as representation of art and literature's based on impersonation. Human beings' desire of purgation by escaping from their own reality is originated from Aristoteles's "catharsis" concept which changing its shape with the development of mass media technology. In the scope of "uses and gratifications theory" grounds on 
several escapes of people via mass communication means. At this point, VR games appear as an important communication means.

Desire of role playing, which is done by new generation using VR environments, is gradually increasing. VR games are used as a new communication environment by a certain mass. VR games which are seen as a hobby these days, maybe will be the only source of entertainment or only communication environment in the future.

As Oskay stated, game, which today has turned into a fantasy, is a kind of entertainment against cruel real life for classes and segments which is commodified or sees commodification as a duty; a type of means that helps people see this crucial reality with semi consciousness in order to arrive to "a form of perceiving and interpreting life in an image that it doesn't express its reality". VR games form a more complex completeness. Integration of users develop fast. There is no standard in the VR games. Games that have a dynamic structure, requires users' to learn interface again. Every new technology carries marks of the one before. According to Binark and Bayraktutan Sütcü, digital games consist, atari, computer, console, mobile and all the different types of games. In this context, VR games are personal communication environments that consist digitality, interactivity, virtuality, variability, modularity features of new communication environment and incorporate these features to the act of playing games. These environments can hide and keep concepts and features which are described as old or conventional.

Game is a life laboratory. Game is a means of conveying emotions for the individual; in the games which make connections between imaginary and real world more meaningful, individuals get to know their life, themselves and their surroundings that are full of unknowns, through game filter. With this feature, VR games become an important communication medium. Today, the best example can be given to new communication mediums are VR games. VR games are popular personal communication means. VR games that are different from one another are being sold in stores and consumed by users. There are several reasons behind popularity of VR games. The main reason is, individual's inability to reach to a certain level or have the characteristic features they aimed at. Individuals who gravitate to different pursuits, fulfill this need via VR games. In this sense, VR games become a new communication means opted for its unlimited features that it offers to users.

Digital games generally gain acceptance by students. At this point game is used as an important means. VR games in education draw attention of students. In this direction, examples and visual transfers via VR games on classes gain importance. Information transferred to students via VR games must come into action through practice or implementation. Through reinforcement of these information with practical works, a faster and more permanent learning is achieved. As a result of this transformation, the information presented to students both become more permanent and learned faster by students. In conclusion, VR games must be used as an important means of communication with characteristics that can direct students' education life.

\section{References}

[1] Algül, A. ve Yengin, D. ve Karadağ, G. ve Övür, A. ve Bayrak, T. (2018). Sanal Gerçekliğin Tetiklediği Semptomlar. İstanbul: İstanbul Aydın Üniversitesi Yayınları.

[2] And, M. (2003). Oyun ve Bügü: Türk Kültüründe Oyun Kavramı. İstanbul: Yapı Kredi Yayınları.

[3] Avedon, E. M. ve Sutton-Smith, B. (1971). The Study of Games. New York: John Wiley \& Sons.

[4] Baudrillard, J. (2005). Simülakrlar ve Simülasyon, (Çev: Oğuz Adanır), Ankara: Doğu Batı Yayınları.

[5] Berne, E. (2019). Games People Play. UK: Penguin Books

[6] Binark, M. ve Bayraktutan Sütcü, G. (2008). Kültür Endüstrisi Ürünü Olarak Dijital Oyun. İstanbul: Kalkedon Yayınları.

[7] Caillois, R. (2001). Man, Play and Game. (Çev: Meyer Baarash). ABD: Glenceo Yayınları.

[8] Castels, M. (2005). Ağ Toplumunun Yükselişi, (Çev: Ebru Kılıç). İstanbul: İstanbul Bilgi Üniversitesi Yayınları. 
[9] Cebeci, Z. (2004), Türkiye'de E-Öğrenim Sorular, Sorunlar ve Bazı Öneriler. Akademik Bilişim Konferansı 11-13 Şubat 2004. KTÜ, Trabzon. Dönmez, Necate Baykoç (1999). Oyun Kitabı. İstanbul: Esin Yayınevi.

[10] Davies, D. (1998). The virtual university: a learning university, Journal of Workplace Learning. Volume: 10 Issue: 4 Aug 1998 pp.175 - 213, MCB University Press Ltd Lynch, M. V.

[11] Geray, H. (2003). Illetişim ve Teknoloji: Uluslar arası Birikim Düzeninde Yeni Medya Politikaları, Ankara: Ütopya Yayınevi.

[12] Huizinga, J. (1995). Homo Ludens Oyunun Toplumsal İşlevi Üzerine Bir Deneme. (Çev. Mehmet Ali Kılıçbay), İstanbul: Ayrıntı Yayınları.

[13] İnnis, H. A. (2006). İmparatorluk ve İletişim Araçları. (Çev: Nurcan Törenli) Ankara: Ütopya Yayınları.

[14] Juul, J. (2005). Half-Real: Video Games Between Real Rules and Fictional Worlds. Cambridge: The MIT Press.

[15] Karasar, Ş. (2004). Eğitimde Yeni İletişim Teknolojileri - İnternet ve Sanal Yüksek Eğitim, The Turkish Online Journal of Educational Technology - TOJET volume 3 Issue 4.

[16] Lister, M. \& Dovey, J. \& Giddings, S. \& Grant, I. \& Kelly, K. (2003). New Media: A Critical Introduction. New York: Routledge.

[17] Manovich, L. (2001). The Language of New Media. Cambridge: MIT Press.

[18] McLuhan, M. ve Powers, B. R. (2001). Global Köy (Çev: Bahar Öcal Düzgören). İstanbul: Scala Yayıncılık.

[19] Onay, Z. ve Yalabık, N. (1998). Bir Üniversitede İnternet Üzerinden Asenkron Öğrenme için Yapılanma Modeli, Türkiye İkinci Uluslararası Uzaktan Eğitim Sempozyumu Bildiriler 4-8 Mayıs 1998.

[20] Oskay, Ü. (1997). İletişimin ABC'si. İstanbul: Der Yayınları.

[21] Postman, N. (2004). Yeni Dünya Düzeni: Teknopoli (Çev: Mustafa Emre Yılmaz). İstanbul: Gelenek Yayıncılık.

[22] Salen, K. \& Zimmerman, E. (2004). Rules of Play: Game Design Fundamentals. Cambridge: MIT Press.

[23] Schank, C. R. (2000). The virtual university, Cyberpsychology \& Behavior. Volume 3, Number1, pp.9-16. Mary Ann Liebert, Inc.

[24] Turkish Language Dictionary, (25.03.2019).

[25] Timisi, N. (2003). Yeni İletişim Teknolojileri ve Demokrasi. Ankara: Dost Kitabevi.

[26] Tilt Brush on Steam.

[27] Wittgenstein, L. (2007). Felsefi Soruşturmalar (Çev: Haluk Barışcan), İstanbul: Metis Yayınları.

[28] Yengin, D. (2012) Dijital Oyunlarda Şiddet. İstanbul: Beta Yayıncılık.

[29] Zichermann, G., \& Cunningham, C. (2011). Gamification by design: Implementing game mechanics in web and mobile apps: O'Reilly Media, Inc. 
